\title{
Viewpoint
}

\section{Introducing new cost effective treatments into the NHS. Surfactant treatment for premature babies: who cares enough to pay?}

\author{
Henry L Halliday
}

The growth in the medicines bill for innovative drugs in the United Kingdom is the lowest in Europe. ${ }^{1}$ Funding new treatments within the NHS is difficult: drug budgets are overspent by significant amounts and mechanisms for obtaining new money for medical advances are simply not working. ${ }^{2}$ Unless there is a more planned approach to spending on drugs - which takes into account the introduction of new treatments - then the time lag before patients can benefit will continue to be unnecessarily long.

The introduction of new treatments is not simply a matter of funding. Other issues include evidence for the effectiveness of the new treatments, the relative benefits of a new treatment against established treatments, and understanding the wider effects of the introduction of a new treatment. Taking a narrow view of the costs of treatment may mask potential cost benefits of a new treatment. The difficulties of introducing a new treatment are well illustrated by the problems experienced in securing the funding and the appropriate service structure for surfactant treatment of preterm babies with respiratory distress syndrome.

\section{Respiratory distress syndrome and surfactant treatment}

Respiratory distress syndrome, a disorder of preterm babies, is caused by deficiency of pulmonary surfactant, ${ }^{3}$ a substance needed for adequate lung expansion after birth. About 5000 babies each year in the United Kingdom develop respiratory distress syndrome - up to two thirds of babies weighing less than $1500 \mathrm{~g}$ at birth. ${ }^{4}$ The mortality rate with assisted ventilation and other supportive treatment is about $25 \%$. Babies with the syndrome have an increased risk of intraventricular haemorrhage, pneumothorax, and bronchopulmonary dysplasia (a form of chronic lung disease often requiring prolonged hospital stay and oxygen treatment).

The relation between respiratory distress syndrome and deficiency of pulmonary surfactant was demonstrated by Avery and Mead in 1959. ${ }^{3}$ Two approaches have been used to correct surfactant deficiency. The first is to give women at risk of preterm delivery glucocorticoid drugs such as betamethasone to stimulate fetal lung maturity, ${ }^{5}$ the second is to replace surfactant after birth by tracheal instillation. ${ }^{6}$ Betamethasone and other glucocorticoid drugs stimulate the synthesis of surfactant in utero and their benefits have been recognised for at least 20 years. ${ }^{5}$ The first successful trial of surfactant replacement was reported about 13 years ago. ${ }^{6}$ Several surfactant preparations are now available to treat or prevent respiratory distress syndrome. These are derived from bovine and porcine lungs - the so called natural surfactants - and from synthetic sources. Synthetic surfactants are protein free and have a slower onset of action.

\section{Randomised clinical trials}

At least 12 randomised clinical trials have shown the efficacy of antenatal glucocorticoids in reducing both the incidence and severity of respiratory distress syndrome and neonatal mortality. ${ }^{7}$ Surfactant treatment for respiratory distress syndrome is also a well studied intervention; over 30 randomised controlled trials involving more than 6000 babies have shown that its use increases survival and reduces the incidence of pulmonary air leaks. ${ }^{89}$

\begin{tabular}{l}
\hline Surfactant treatment for \\
respiratory distress syndrome is a \\
well studied intervention. . . \\
\hline \hline
\end{tabular}

The overall effect of both types of drugs is an approximate $40 \%$ reduction in the odds of death. ${ }^{7}$ Surfactant replacement leads to a $70 \%$ reduction in the odds of pulmonary air leaks for natural preparations and a $30 \%$ reduction for synthetic preparations. 9 The incidence of intraventricular haemorrhage and bronchopulmonary dysplasia are not significantly reduced by surfactant treatment and, in some circumstances, the incidence of patent ductus arteriosus is increased. ${ }^{8} 9$ Long term follow up studies do not show any increase in the frequency of neurodevelopmental or pulmonary sequelae despite increased survival of immature babies treated with surfactant. ${ }^{1011}$ 


\section{Cost and cost effectiveness}

Betamethasone is a relatively inexpensive drug costing about $£ 25$ for a course of treatment. The costs per extra survivor are also lower for antenatal glucocorticoid treatment than for surfactant treatment. ${ }^{12} 13$

Two surfactant preparations, Exosurf Neonatal (a synthetic surfactant) and Survanta (a natural surfactant), currently have product licences in the United Kingdom. Both cost $£ 314.29$ per phial, which provides enough surfactant for one treatment dose for a baby of up to $1600 \mathrm{~g}$ birth weight. Two doses are recommended for Exosurf and up to four doses for Survanta, giving a cost per treatment course of between $£ 628.58$ and $£ 1257.16$. Competitor surfactant preparations are unlikely to be cheaper.

Exogenous surfactants are cost effective. The reduction in mortality which results from the use of surfactant to treat severe respiratory distress syndrome in immature infants may be associated with increased total costs of care. ${ }^{14}$ However, there are savings of between $\$ 10000$ and $\$ 15500$ (at 1988 prices) per survivor when a natural surfactant Infasurf is given prophylactically. ${ }^{15} 16$

The cost per quality adjusted life year (QALY) has been calculated at $£ 710$ (at 1989 prices) per life year gained for another natural surfactant, Curosurf, ${ }^{14}$ and $\$ 3300$ (at 1990 prices) per life year gained for a synthetic surfactant, Exosurf, ${ }^{17}$ when each is used to treat severe respiratory distress syndrome. When Exosurf is used to treat larger babies $(\geq 1250 \mathrm{~g}$ birth weight) there is a net saving due to reduction in the duration of intensive care and an insignificant increase in survival rate. ${ }^{17}$

Thus surfactant treatment saves lives if given to very immature babies but may increase overall treatment costs, whereas surfactant treatment saves money if given to more mature babies, whose overall survival is not improved. Clearly judgments about administering surfactant need to be made in the context of the wider issues of neonatal intensive care by those who are specialists in neonatal care.

Recent evidence suggests that babies of mothers given glucocorticoids respond better to surfactant treatment than those whose mothers were not given antenatal steroids. ${ }^{18}$ The combination of antenatal corticosteroids and postnatal prophylactic surfactant seems to be the most cost effective approach to improving the outcome in babies of less than 30 weeks' $^{\prime}$ gestation ${ }^{12}$ because it produces the greatest number of survivors and the lowest number of days of intensive care and high dependency care in hospital. ${ }^{13}$

\section{Service considerations}

Surfactant treatment needs to be given with the support of facilities for neonatal intensive care. Specialist services have been somewhat overlooked in the latest round of NHS reforms, and there is evidence that the roles of regional perinatal and neonatal centres are being limited and that part time neonatology in small hospitals is being encouraged. Such changes in service provision, although possibly financially expedient in the short term, could effectively reverse the improvement in neonatal care over the past 30 years, ${ }^{19}$ at a time when current neonatal care should be

.. changes in service provision
. could effectively reverse the
improvement in neonatal care
over the past 30 years...

enhanced by proper delivery of effective new treatments. The decrease in workload reported by some regional perinatal centres through small babies being cared for in district general hospitals without the advantage of the expertise of specialist neonatal care ${ }^{19}$ suggests that the service structure needed for the effective introduction of surfactant is being eroded. Anecdotal reports of the use of surfactant for small babies being restricted because of cost illustrate the dangers of a haphazard and unplanned introduction of a new treatment.

Although guidelines for the staffing and equipping of neonatal intensive care units exist, ${ }^{2021}$ no system of accreditation of these units has been developed, and measures of assessment of the quality of care and outcome barely exist. These problems are being mirrored in the United States, where deregionalisation of high risk perinatal and neonatal care has placed the whole health care system on the verge of bankruptcy. ${ }^{22}$ It is perhaps not surprising that there has been much confusion and uncertainty about how to introduce an effective new treatment.

A coherent service for the care of preterm infants should include agreed criteria for transfer to regional centres ${ }^{20}$ and acknowledgment of the indications for surfactant treatment $^{23}$ (The British Association of Perinatal Medicine is currently producing guidelines for UK paediatricians.) As the combination of antenatal corticosteroids and postnatal surfactant seems to be most cost effective $^{12} 13$ any approach to an improved outcome for respiratory distress syndrome and any service for preterm infants must include a coordinated approach with neonatal specialists and obstetricians working together.

\section{How to progress}

The introduction of any new treatment into the NHS is likely to be restrained by more than simply concern about funding. For surfactant treatment, some regions have dealt with the funding issue by the direct approach of top slicing adequate funds for purchasing surfactant for regional neonatal centres. But this option is unlikely to be available for future innovative treatments. A strategy is needed which will allow for a measured introduction of new treatments such as surfactant. 
Elements of such a strategy would assure that contracts reflect significant drug costs and perhaps would remove drug costs for new treatments to a research and development fund. ${ }^{2}$ At the same time it is clearly important that the mechanisms exist which ensure that currently used treatments are properly assessed for their benefits and cost effectiveness. $^{24}$

But as the introduction of surfactant has illustrated, any new treatment needs to be understood in the whole context of service provision and of other approaches to improving outcome. There is a real danger that the new structures of the NHS will encourage a more fragmented activity driven approach to care. New treatments should not be seen as individual units of activity with an unwelcome price tag but as part of the whole context of provision of a particular service. Researchers must take up the task of describing findings in terms of service provision. Clinicians and managers must understand the wider implications of introducing new treatments and work together towards coordinating the introduction of new effective treatments. Until these problems have been solved British patients will continue to be denied the advantages of newer medicines. ${ }^{1}$

1 Griffin JP, Chew RB. Growth in prescription medicines expenditure: a European comparison. $\mathcal{f} R$ Coll Physicians Lond 1993;27:54-5.

2 Barrett CW, Tugwell C, James C. Preparing realistic "budgets" for medicines: a need for change. Hospital Update 1992;18:148-51.

3 Avery ME, Mead J. Surface properties in relation to atelectasis and hyaline membrane disease. Am $\mathcal{F}$ Dis Child 1959;97:517-23.

4 Corcoran D, Halliday HL. Surfactant replacement for the prevention and treatment of respiratory distress syndrome. Postgraduate Doctor 1992;15:315-21.

5 Liggins GC, Howie RN. A controlled trial of antepartum glucocorticoid treatment for prevention of the respiratory distress syndrome in premature infants. Pediatrics 1972;50:515-25.
6 Fujiwara T, Maeta H, Chida S, Morita T, Watabe Y, Abe Y. Artificial surfactant therapy in hyaline-membrane disease. Lancet 1980;i:55-9.

7 Crowley P, Chalmers I, Keirse MJNC. The effect of corticosteroid administration before preterm delivery: an overview of the evidence from controlled trials. $\mathrm{Br} F$ Obstet Gynaecol 1990;97:11-25.

8 Soll RF, McQueen MC. Respiratory distress syndrome. In: Sinclair JC, Bracken MB, eds. Effective care of the newborn infant. Oxford: Oxford University Press, 1992:325-58.

infant. Oxford: Oxford University Press, 1992:325-58.
9 Halliday HL. Other acute lung disorders. In: Sinclair JC, Balliday HL. Other acute lung disorders. In: Sinclair JC,
Bracken MB, eds. Effective care of the newborn infant. Bracken MB, eds. Effective care of the newborn
Oxford: Oxford University Press, 1992:359-84.

10 Halliday HL. Follow up data from babies treated with surfactant. In: Bevilacqua G, Parmigiani S, Robertson B, eds. Surfactant in clinical practice. Chur: Harwood Academic, 1993: 149-56.

11 Halliday HL. Surfactant replacement. In: Klaus $\mathrm{MH}$, Fanaroff AA, eds. Neonatal and perinatal medicine 1991 yearbook. London: Yearbook Medical Publishers, 1992:13-21.

12 Mugford M, Piercy J, Chalmers I. Cost implications of different approaches to the preventions of respiratory different approaches to the preventions of respirator
distress syndrome. Arch Dis Child 1991;66:757-64.

13 Egberts J. Estimated costs of different treatments of the respiratory distress syndrome in a large cohort of preterm infants of less than 30 weeks of gestation. Biol Neonate 1992;61 (suppl 1):59-65.

14 Tubman TRJ, Halliday HL, Normand C. Cost of surfactant replacement treatment for severe neonatal respiratory distress syndrome: a randomised controlled trial. $B M \mathcal{F}$ 1990;301:842-5.

15 Maniscalco WM, Kendig JG, Shapiro DL. Surfactant replacement therapy: impact on hospital charges for premature infants with respiratory distress syndrome. Pediatrics 1989;83:1-6.

16 Shennan A, Dunn M, Possmayer F. Cost effectiveness of single dose surfactant prophylaxis in infants of less than single dose surfactant prophylaxis in infants of
30 weeks' gestation. Pediatr Res 1989;25:231A.

17 Long W, Wold D, Corbet A. The economic impact of synthetic surfactant - one year follow-up. Adv Neonatal 1992; The Wellcome Foundation pp 9-10.

18 Farrell EE, Silver RK, Kimberlin LV, Wolf ES, Dusik JM. Impact of antenatal dexamethasone administration on respiratory distress syndrome in surfactant-treated infants. Am 7 Obstet Gynecol 1989;161:628-33.

19 Pope C, Wild D. Putting the clock back 30 years: neonatal care since the 1991 NHS reforms. Arch Dis Child 1992;62:879-81.

20 Royal College of Physicians of London. Medical care of the newborn in England and Wales. Report. London: RCP, newbor

21 Report of working group of the British Association of Perinatal Medicine and Neonatal Nurses Association on categories of babies requiring neonatal care. Arch Dis Child 1992;67:868-9.

22 Stahlman MT. Improving health care to neonates in the United States. Am F Dis Child 1993;147:516.

23 Committee on Fetus and Newborn, American Academy of Pediatrics. Surfactant replacement therapy for respiratory distress syndrome. Pediatrics 1991;87:946-7.

24 Williams R. Can we afford medical advances? $f R$ Coll Physicians Lond 1993;27:70-2. 